Article

\title{
Nasal Colonization of Humans with Occupational Exposure to Raw Meat and to Raw Meat Products with Methicillin-Susceptible and Methicillin-Resistant Staphylococcus aureus
}

\author{
Christiane Cuny ${ }^{1, *}$, Franziska Layer ${ }^{1}$, Sonja Hansen ${ }^{2}$, Guido Werner ${ }^{1}$ and Wolfgang Witte ${ }^{1}$ \\ 1 Robert Koch Institute, Wernigerode Branch, 38855 Wernigerode, Germany; layerf@rki.de (F.L.); \\ wernerg@rki.de (G.W.); EWWitte@t-online.de (W.W.) \\ 2 Institute of Hygiene and Environmental Medicine, Charité, 12203 Berlin, Germany; sonja.hansen@charite.de \\ * Correspondence: cunych@rki.de; Tel.: +49-30-18754-4346
}

Received: 6 March 2019; Accepted: 28 March 2019; Published: 30 March 2019

check for updates

\begin{abstract}
Livestock-associated methicillin-resistant Staphylococcus aureus (LA-MRSA) is widely disseminated as a nasal colonizer of conventionally raised livestock and of humans subjected to occupational exposure. Reports on contamination of raw meat raise the question as to whether occupationally exposed food handlers are at particular risk of nasal colonization by LA-MRSA. Here, we report the results from a cross-sectional study on nasal S. aureus/MRSA colonization of butchers, meat sellers, and cooks in Germany. We sampled 286 butchers and meat sellers in 26 butcheries and 319 cooks handling meat in 16 professional canteen kitchens. Swabs were processed on both blood agar plates and MRSA-selective plates. MRSA were confirmed by PCR for mec genes and by broth microdilution. All isolates were subjected to molecular typing. PCR for markers useful to differentiate human-adapted and animal-adapted subpopulations was performed due to the presence of clonal complexes known to occur in both livestock and humans (CC5, CC7, CC8, CC9, and CC398). Only two participants $(0.33 \%)$ were colonized by MRSA (Hospital-associated MRSA ST22). Nasal colonization by methicillin-susceptible S. aureus (MSSA) was detected in $16.6 \%$ of cooks and in $26.2 \%$ of butchers and meat sellers. Among 16 of the isolates attributed to CC7, three were negative for the immune evasion gene cluster, suggesting an animal origin. Isolates attributed to CC5, CC8, and CC398 were negative for markers typical of animal-adapted subpopulations. The occupational handling of raw meat and raw meat products was not associated with nasal colonization by LA-MRSA.
\end{abstract}

Keywords: MRSA; meat; occupational exposure

Key Contribution: Raw meat and raw meat products are known to be contaminated with livestock-associated MRSA and may be acquired by humans handling these products. Nasal colonization with LA-MRSA was not detected in 605 humans with occupational exposure to raw meat.

\section{Introduction}

Staphylococcus aureus (S. aureus) is widely disseminated as a colonizer and as an infectious agent among humans and other animal hosts. The species can be subdivided into several clonal complexes by means of multi locus sequence tying. Some clonal complexes are mainly associated with particular host species, while others are less host specific (for review see Reference [1]). Human- and animal-adapted subpopulations differ by various genetic adaptations [2]. For example, the immune evasion gene cluster (IEC) is usually contained by human-adapted S. aureus, but it is mainly absent in the animal-adapted subpopulations [3]. Therefore, there are particular markers for the discrimination of human- and 
animal-adapted bacterial strains [4-6]. Livestock-associated MRSA (LA-MRSA) usually represent discrete subpopulations of clonal complexes of well-known human adapted subpopulations of $S$. aureus [2]. In particular, LA-MRSA CC398 (attributed to clonal complex CC398) has emerged in food production animals such as pigs, veal calves, and poultry worldwide (for review see [7]). Globally, the predominant lineages found in studies on LA-MRSA in swine populations are ST398 (most European [8] and some North American studies [9]), ST9 (most Asian studies [10]) and ST5 (North American studies [9]). It was scarcely surprising that LA-MRSA was also identified on retail meat of different animal origins (for review see [11]). A German study reported the contamination of $2.8 \%$ of pork end products with LA-MRSA CC398 [12], and it was subsequently detected in 32\% of German turkey meat samples [13]. Furthermore, LA-MRSA CC398 was identified in the thawing liquid of 33\% of broiler chicken carcasses [14]. Involvement of MSSA/MRSA CC398 in food intoxication has not been reported to date, and isolates attributed to this clonal complex only rarely contain enterotoxin genes [15]. Nasal colonization with LA-MRSA is frequent in humans with occupational livestock exposure (for review see [16]) and can persist after interruption of exposure [17,18]. Colonization of familial contacts of exposed persons is more rarely observed [19]. As known for S. aureus in general, humans colonized with LA-MRSA CC398 have an increased risk of developing various kinds of infections. LA-MRSA CC398 is not less virulent in humans than S. aureus in general [20]. More recently, colonization and infections of LA-MRSA CC398 were also reported for patients without any association of themselves or of their family members with livestock farming [21]. In addition to living in close vicinity to livestock farms from which LA-MRSA are exhausted, acquisition by handling contaminated meat and meat products should be taken into account. There are only a few studies that have addressed this question. MRSA colonization was identified in $1.15 \%$ of food handlers working in commercial kitchens in Hong Kong [22]. In the same city, 5.6\% of butchers were colonized, of which $3 \%$ of them carried LA-MRSA ST9 [23]. Nasal MRSA colonization was not detected in a pilot study in the Netherlands involving 95 professional meat handlers [24]. Here, we report results from a cross-sectional study on nasal MRSA colonization of butchers and meat sellers working in butcheries and of cooks working in canteen kitchens. Methicillin-susceptible S. aureus (MSSA) isolates from the nasal swabs of handlers of both raw meat and raw meat products were also characterized in order to obtain a more general impression of the possibility of acquisition of $S$. aureus of animal origin.

\section{Results}

\subsection{Characteristics of The Sample}

Among the 605 persons who agreed to provide a nasal swab and to fill out a questionnaire on descriptive characteristics, 286 were butchers and meat sellers and 319 were cooks. The whole sample included 394 females (65.1\%). A previous hospital stay was reported by $37(6.1 \%)$ of the participants, previous prescription of antibiotics by $60(9.9 \%)$, diabetes mellitus by $23(3.8 \%)$, and superficial skin disorders by $27(4.4 \%)$. Furthermore, $326(53.9 \%)$ reported regular contact with companion animals. In addition to contact with companion animals (more frequent in the butchers and meat sellers' groups) and hospital stay (more frequent in the cooks' group), differences between both groups concerning the other variables were not significant (Table 1).

\subsection{S. aureus Nasal Carriage}

S. aureus was detected in 130 participants (21.5\%; 95\% confidence interval (CI) $18.2-24.8 \%$ ). Carriage was significantly more frequent in males than in females $(28.4 \%$; $95 \%$ CI $22.2-35.1 \%$ versus $17.8 \% ; 95 \%$ CI $14.2 \%-21.8 \%, p=0.003$, OR 1.83 [1.23-2.73]). Similar results were obtained when both occupational groups were analyzed separately (Table S1). To our surprise, colonization was significantly more frequently detected in butchers and meat sellers than in cooks (26.9\%, CI 63-93\% vs. $16.6 \%$, CI $41-68 \%$ ). There were, however, no significant differences in the frequency distribution of characteristics which might influence S. aureus nasal carriage (Table S1). Besides regular pet animal 
contact, the number of persons with diabetes mellitus, skin disorders, previous hospital stay, and antibiotic prescription was too low for statistical analysis of $S$. aureus carriage in both occupational groups. Differences in S. aureus carriage rates between persons with and without pet animal contact were not significant; therefore, the difference between both occupational groups was not influenced by this variable.

Table 1. Descriptive characteristics of the study participants.

\begin{tabular}{|c|c|c|c|c|c|c|c|c|}
\hline \multirow{3}{*}{ Sex } & \multirow{3}{*}{$\begin{array}{l}\text { female } \\
\text { male }\end{array}$} & \multicolumn{2}{|c|}{ All $(n=605)$} & \multicolumn{2}{|c|}{$\begin{array}{l}\text { Butchers, Meat } \\
\text { Sellers }(n=286)\end{array}$} & \multicolumn{2}{|c|}{ Cooks $(n=319)$} & \multirow{3}{*}{$\begin{array}{c}p^{1} \\
0.158\end{array}$} \\
\hline & & 394 & $65.1 \%$ & 195 & $68.2 \%$ & 199 & $62.4 \%$ & \\
\hline & & 211 & $34.8 \%$ & 91 & $31.8 \%$ & 120 & $37.6 \%$ & \\
\hline \multirow{6}{*}{ Age groups } & $<20$ & 12 & $2 \%$ & 9 & $3.1 \%$ & 3 & $0.9 \%$ & 0.0986 \\
\hline & $21-30$ & 81 & $13.4 \%$ & 33 & $11.50 \%$ & 48 & $15.0 \%$ & 0.211 \\
\hline & $31-40$ & 116 & $19.2 \%$ & 41 & $14.30 \%$ & 75 & $23.5 \%$ & 0.058 \\
\hline & $41-50$ & 150 & $24.8 \%$ & 80 & $30.0 \%$ & 70 & $22.0 \%$ & 0.169 \\
\hline & $51-60$ & 182 & $30.0 \%$ & 92 & $32.2 \%$ & 90 & $28.2 \%$ & 0.313 \\
\hline & $>61$ & 64 & $10.6 \%$ & 31 & $10.8 \%$ & 33 & $10.3 \%$ & 0.042 \\
\hline Hospital stay & & 37 & $6.1 \%$ & 8 & $2.8 \%$ & 29 & $9.0 \%$ & 0.022 \\
\hline Antibiotic prescription & & 60 & $9.9 \%$ & 22 & $7.6 \%$ & 38 & $11.0 \%$ & 0.11 \\
\hline Diabetes mellitus & & 23 & $3.8 \%$ & 12 & $4.2 \%$ & 11 & $3.4 \%$ & 0.789 \\
\hline Skin disorders & & 27 & $4.5 \%$ & 19 & $6.6 \%$ & 8 & $2.5 \%$ & 0.023 \\
\hline Pet animal contact & & 326 & $53.90 \%$ & 176 & $61.5 \%$ & 150 & $47.0 \%$ & 0.0004 \\
\hline
\end{tabular}

\subsection{Antibiotic Resistance}

All of the 53 isolates obtained from 319 cooks and 75 of the 77 isolates obtained from 286 butchers and meat sellers were phenotypically susceptible to oxacillin and cefoxitin and negative for mecA. Seven of these isolates exhibiting an MIC of $1.0 \mathrm{mg} / \mathrm{L}$ for oxacillin were negative for mecC by PCR. Among the 77 isolates obtained from butchers and meat sellers, only two exhibited resistance to oxacillin and cefoxitin. Both MRSA isolates contained mecA on SCCmecIV and exhibited spa-type t032, which is typical for hospital-associated MRSA ST22. Altogether MRSA was detected in two participants $(0.33 \%$; $95 \%$ CI $0-1.1 \%)$ that were both females who had worked as meat sellers and had an age range of 41-50 years, with no report of a previous hospital stay, a previous antibiotic prescription, diabetes mellitus, or skin disorder. The phenotypical antibiotic resistance patterns of the 130 isolates investigated are shown in Table 2. Among the isolates, $43 \%$ were susceptible to all antibiotics tested. Amongst the MSSA, resistance to penicillin was most common (50\%), followed by resistance to erythromycin $(7.8 \%)$. Resistance to both penicillin and erythromycin was found in seven isolates, three of which (spa-types $\mathrm{t} 571$ and t1451) were attributed to CC398. There is a limitation with respect to no checking erythromycin resistant isolates for the presence of the inducible macrolide-lincosamide-streptogramin B phenotype.

\subsection{Results from Typing}

As shown in Table 3, the isolates exhibited a total of 52 spa-types. Based on related repeat patterns, the observed spa-types were grouped into 6 spa-clonal complexes (spa-CCs). Eleven spa-types were singletons (repeat pattern not associated with the patterns of other isolates from this study), four revealed as non-typeable, and one was excluded because it contained less than five repeats. The isolates were attributed to 14 MLST-based clonal complexes (CCs). Spa-types t084 $(n=14)$, t091 $(n=14)$, and t008 $(n=9)$ were particularly frequent. Because of related spa-repeat patterns, isolates attributed to MLST-sequence type clonal complexes CC7 and CC15 are grouped in spa-CC spa-CC084/346. Spa-CC045 usually includes S. aureus isolates attributed to CC15 by MLST. Attribution to CCs for 
isolates from both occupational groups of carriers is shown in Table S2. Subpopulations adapted to humans as well as to animals are known for CCs 5, 8, 9, and 398, and they can be discriminated by PCR as described in the materials and methods section. In addition, S. aureus CC7 was observed in humans as well as in chicken [25]. Among the 16 isolates attributed to CC7, three were negative for IEC which suggests an animal origin. All of the seven isolates attributed to clonal complex 5 were negative for pathogenicity island SaPIAv, and all of the 13 isolates attributed to CC8 were negative for lukM and for seo141, respectively, suggesting no animal origin. The four isolates attributed to CC398 were assigned to the human-adapted subpopulation (Table S3).

Table 2. Antibiotic resistance patterns of $S$. aureus $(n=130)$ isolated from nasal swabs of cooks, butchers, and meat sellers.

\begin{tabular}{cccc}
\hline $\begin{array}{c}\text { Antibiotic Resistance } \\
\text { Phenotypes }\end{array}$ & Frequency & $\begin{array}{c}\text { Resistance to Singular Antibiotics } \\
\text { in MSSA }(\boldsymbol{n = 1 2 8 )}\end{array}$ & Frequency \\
\hline Susceptible & $56(43.0 \%)$ & PEN & $64(50.0 \%)$ \\
PEN & $55(42.3 \%)$ & ERY & $13(10.1 \%)$ \\
PEN, ERY & $7(5.4 \%)$ & CLI & $1(0.8 \%)$ \\
PEN, TET & $1(0.77 \%)$ & TET & $2(1.6 \%)$ \\
PEN, CIP & $1(0.77 \%)$ & CIP & $3(2.3 \%)$ \\
PEN, OXA, CIP, MFL & $1(0.77 \%)$ & & \\
PEN, OXA, ERY, CLI, & $1(0.77 \%)$ & & \\
CIP & $5(3.9 \%)$ & & \\
ERY & $1(0.77 \%)$ & & \\
TET & $2(0.15 \%)$ & & \\
CIP & & & \\
\hline
\end{tabular}

Abbreviations: $\mathrm{CIP}=$ ciprofloxacin, $\mathrm{CLI}=$ clindamycin, $\mathrm{ERY}=$ erythromycin, $\mathrm{MFL}=$ moxifloxacin, $\mathrm{OXA}=$ oxacillin, PEN = benzylpenicillin, TET = tetracycline. Antibiotics tested: penicillin, oxacillin, cefoxitin, fosfomycin, gentamicin, linezolid, erythromycin, clindamycin, tetracycline, tigecycline, vancomycin, teicoplanin, ciprofloxacin, mupirocin, moxifloxacin, daptomycin, fusidic acid-sodium, rifampicin, and trimethoprim/sulfamethoxazole.

Table 3. Spa-types and spa-clonal complexes of methicillin-susceptible S. aureus (MSSA) and methicillinresistant $S$. aureus (MRSA).

\begin{tabular}{|c|c|c|c|c|}
\hline \multirow{2}{*}{$\frac{\text { spa-CC }}{\text { Singleton }}$} & \multirow{2}{*}{$\frac{\text { spa-Types (No. Isolates) }}{\mathrm{t} 127(3)}$} & \multirow{2}{*}{$\frac{\text { No. Isolates }}{3}$} & \multicolumn{2}{|c|}{ Attribution to CC (ST) } \\
\hline & & & CC1 & $3(2.3 \%)$ \\
\hline spa-CC002 & t002(5), t1265(1), t1794(1) & 7 & CC5 & $7(5.4 \%)$ \\
\hline spa-CC084/346 & t091(14), t1943(1) & 15 & CC7 & $16(12.3 \%)$ \\
\hline Non typeable & $\mathrm{t} 2932(1)$ & 1 & & \\
\hline spa-CC121 & t008(9), t121(2), t190(1), t292(1) & 13 & CC8 & $13(10.0 \%)$ \\
\hline Singleton & $\mathrm{t} 209(1)$ & 1 & CC9 & $1(0.8 \%)$ \\
\hline spa-CC084/346 & $\mathrm{t} 084(14), \mathrm{t} 346(4), \mathrm{t} 499(2), \mathrm{t} 491(1)$ & 21 & CC15 & $25(19.2 \%)$ \\
\hline Non typeable & 15546(1), t15664(1), t15712(1) & 3 & & \\
\hline Excluded & $\mathrm{t} 5497(1)$ & 1 & & \\
\hline spa-CC005 & $\begin{array}{l}\mathrm{t} 005(12), \mathrm{t} 006(1), \mathrm{t} 032(2){ }^{1}, \mathrm{t} 223(1) \\
\text { t310(1), t449(1), t17201(1) }\end{array}$ & 19 & $\mathrm{CC} 22$ & $21(16.2 \%)$ \\
\hline Singletons & $\mathrm{t} 417(1), \mathrm{t} 420(1)$ & 2 & & \\
\hline spA-CC012 & $\begin{array}{c}\mathrm{t} 012(6), \mathrm{t} 018(2), \mathrm{t} 021(2), \mathrm{t} 122(1) \\
\mathrm{t} 253(1), \mathrm{t} 338(1), \mathrm{t} 789(1)\end{array}$ & 14 & СС30 & $15(11.5 \%)$ \\
\hline Singleton & $\mathrm{t} 1827(1)$ & 1 & & \\
\hline No founder & $\mathrm{t} 136(1), \mathrm{t} 166(1)$ & 2 & CC34 & $4(3.0 \%)$ \\
\hline Singleton & $\mathrm{t} 089(2)$ & 2 & & \\
\hline spa-CC015 & $\begin{array}{c}\mathrm{t} 015(7), \mathrm{t} 073(4), \mathrm{t} 331(1), \mathrm{t} 505(1) \\
\mathrm{t} 15726(1)\end{array}$ & 14 & CC45 & $16(12.3 \%)$ \\
\hline Singletons & $\mathrm{t} 004(1), \mathrm{t} 1460(1)$ & 2 & & \\
\hline Singleton & $\mathrm{t} 056(2)$ & 2 & CC101 & $2(1.5 \%)$ \\
\hline Singleton & $\mathrm{t} 159(2)$ & 2 & CC121 & $2(1.5 \%)$ \\
\hline Singleton & $\mathrm{t} 493(1)$ & 1 & ST182 & $1(0.8 \%)$ \\
\hline No founder & $\mathrm{t} 571(2), \mathrm{t} 1451(2)$ & 4 & СС398 & $4(3.0 \%)$ \\
\hline Total & & 130 & & \\
\hline
\end{tabular}

${ }^{1}$ Both isolates were MRSA. 


\section{Discussion}

The S. aureus carriage rate found in our cross-sectional study for butchers and meat sellers roughly corresponds to results from recent studies in Central, North Western, and Northern Eastern Germany [26-28]. The carriage rate was higher in men in both occupational groups. This corresponds to results from previous German studies [26,27] and to observations in different countries [29]. The reasons for the surprisingly lower carriage rate in cooks remain unclear. Both occupational groups did not differ significantly by gender distribution nor to other conditions which are known to predispose to nasal carriage of $S$. aureus, such as diabetes mellitus and superficial skin disorders [29]. S. aureus carriage rates seem to decrease with age [30]. However, there were no significant differences in age group distribution between both occupational groups. Thus, we cannot exclude an influence of the work habit. Inhalation of antibacterial compounds that evaporate from the cleanser at the end of the working day when warm stoves are cleaned might suppress colonization. Another explanation would be that cooks more frequently wash their hands while on duty and might get used to this in general. Hands seem to play an important role in human to human transmission via contamination of surfaces [31,32]. Furthermore, we have to consider that although sampling only once for each person captures persistent as well as transient colonization, there are also intervals with no demonstration of S. aureus in persistent carriers $[26,33]$.

Carriage of MRSA was found in two persons from the butcher's group $(0.7 \%)$. This observation corresponds to data from recent population-based studies in Germany $[26,27,34]$. Both MRSA isolates from butchers in this study were attributed to clonal lineage ST22, a hospital-associated epidemic MRSA lineage which is disseminated worldwide [35]. It is particularly abundant in Germany where it accounts for $84.4 \%$ of all MRSA isolates from wound infections and bacteremia [36]. Emergence of HA-MRSA ST22 in the community was also reported from Portugal [37]. In contrast to reports from Hong Kong, LA-MRSA colonization was not observed in humans with occupational exposure to raw meat and raw meat products in our study. In addition to different working habits, this might be due to different capacities of LA-MRSA CC9 and LA-MRSA CC398 for human nasal colonization. Furthermore, the low quantities of MRSA on retail meat reported so far $[24,38,39]$ may not be sufficient for acquisition of nasal colonization by handling these products. On the other hand, an epidemiological study in the Netherlands identified regular consumption of poultry as a risk factor for acquisition of nasal MRSA colonization [40].

The frequency of resistance to penicillin among the MSSA corresponded to data from previous studies on MSSA from nasal colonization in Germany [27,28]. Resistance to erythromycin was slightly more frequent and corresponded to data reported for MSSA from infections in the German community [41]. The frequency to tetracycline was low. Tetracycline resistance is usually prevalent in MSSA and MRSA from livestock, and the same applies to erythromycin resistance (for European studies [42-44]).

Particular CCs were abundant among the MSSA, including CC15 and CC22, followed by CCs 7, 8, and 45. Besides CC7, this corresponds to data from a previous study in North-Eastern Germany [28]. However, isolates attributed to CC25 were also prevalent in this region but absent among the isolates from the study presented here. These observations suggest regional differences in the population structure of $S$. aureus colonizing humans. Colonization with MSSA of probable animal origin was also rare; only three isolates attributed to ST7 were negative for IEC. S. aureus CC7 is not only prevalent in human colonization but also identified from chicken meat [25].

In summary, our findings suggest that the risk of LA-MRSA colonization from handling meat seems to be very low for professionals working in canteen kitchens and butcheries. Most probably, the general population may be at an even lower risk, good kitchen hygiene practice provided. 


\section{Materials and Methods}

\subsection{Study Participants}

In Germany, food-workers are not routinely screened for S. aureus carriage. Mediated by the management of butcheries and canteen kitchens, butchers, meat sellers, and cooks were contacted for voluntary participation in the study by an information letter. In case of agreement and return of a declaration of consent they obtained swabs for self-collection of nasal swabs, an instruction for self-collection, and a short questionnaire asking for information on basic demographic characteristics such as age, sex, and potential risk factors for colonization with methicillin-sensitive and methicillin-resistant S. aureus (MSSA and MRSA). Feasibility of self-collection was reported previously [45]. A total of 286 butchers and meat sellers from 26 butcher's shops as well as 319 cooks from 16 canteen kitchens were enrolled in the study. Companies participating were located in federal states Saxony-Anhalt, Lower Saxony, Saxony, North-Rhine-Westphalia, and Thuringia. The study was approved by the ethical committee of the medical faculty of Magdeburg University (\#33/14).

\subsection{Sampling and Primary Diagnostics}

For taking nasal swabs, the transystem ${ }^{\circledR}$ from Hain- Lifescienes, 72,147 Nehren, Germany, was used. Both nostrils of each participant were sampled by the same swab. After non-selective enrichment in cation-adjusted Mueller-Hinton broth, aliquots were streaked on CHROMagar ${ }^{\mathrm{TM}}$ MRSA from Becton Dickinson (Heidelberg, Germany) and in parallel on Mueller-Hinton blood agar plates (Oxoid, Wesel, Germany). After incubation at $37^{\circ} \mathrm{C}$ for $24 \mathrm{~h}$, one suspicious colony was subcultured on sheep blood agar, except differences in colonial morphology and haemolysis. Confirmation of $S$. aureus was performed by demonstration of the clumping factor and additionally by the tube coagulase test. For the detection of the clumping factor, we used a solution of fibrinogen from human plasma (Sigma-Aldrich, Taufkirchen, Germany) of $2 \mathrm{mg} / \mathrm{mL} 0.85 \% \mathrm{NaCl}$ ). For the tube coagulase test, we used fresh ready to use human plasma provided by DRK blood donation service, 31,831 Springe, Germany. In the case of negative results, we performed PCR for the S. aureus specific region of $t u f$ by use of primers and PCR conditions according to Reference [46]. For PCR, genomic DNA was extracted from S. aureus grown in nutrient broth by use of the DNeasy tissue kit (Qiagen, Hilden, Germany), and lysostaphin (100 mg/L; Sigma, Taufkirchen, Germany) for bacterial lysis.

\subsection{Typing and Further Characterization}

All S. aureus isolates were subjected to spa typing as described previously [47]. Related spa types (costs $\leq 4$ ) were grouped into spa-clonal clusters (spa CC) using the BURP algorithm (Ridom StaphType software version 2.2.1, RidomGmbH, Würzburg, Germany). Spa-CCs were allocated to MLST CCs through the SpaServer database (www.spaserver.ridom.de) and the database of the German National Reference Center for Staphylococci and Enterococci. For a subset of isolates, MLST was performed as described [48]. Antimicrobial susceptibility testing was performed by using the broth microdilution method and applying EUCAST breakpoints (version 8.1), for interpretation of the results (www.eucast.org). Test panels were from own production. The following antibiotics were tested: penicillin, oxacillin, cefoxitin, fosfomycin, gentamicin, linezolid, erythromycin, clindamycin, tetracycline, tigecycline, vancomycin, teicoplanin, ciprofloxacin, mupirocin, moxifloxacin, daptomycin, fusidic acid-sodium, rifampicin, and trimethoprim/sulfamethoxazole.

PCR for mecA, mecC, and SCCmec was performed as described previously [19,49]. Markers for attribution of isolates to human- and animal adapted subpopulations of particular clonal lineages were detected by PCR as described below.

PCR for IEC (sak, chp, scn, sea, sep) was performed for isolates attributed to CC7 and CC9 as described previously [47]. The avian subpopulation of CC5 contains pathogenicity island SaPIAv [4], and primers SAPIAvF1/R1 for detection were used as described [4]. There is obviously a bovine subpopulation in CC8 which contains lukM [5] as known for clonal lineages typically associated with 
ruminants [50]. Primers used for detection correspond to Reference [51]. Furthermore, the bovine subpopulation of ST8 harbors nucleotide sequence of 26 in SCCM186 [5], a homologue of SEO-141 in S. epidermidis ATCC12228. Primers used for detection were 5'-ATGGGAATCAAAGACGTA and 5'CAATTGTTATTATCCTGCTGTC (134366-134383 and 134484-13458, respectively in NC_004461). For CC398, an ancestral human-adapted and an animal-adapted subpopulation are known. Rapid discrimination was performed by singleplex PCR for the canonical single nucleotide polymorphism in the SAPIG_2511 locus (nucleotide 2,597,585 in AM990992 vs. nucleotide 2,440,348 in CP0003045), according to published protocols [42]. The cycling scheme for these PCR reactions was: $95{ }^{\circ} \mathrm{C}, 300 \mathrm{~s}$ [95 $\left.{ }^{\circ} \mathrm{C}, 30 \mathrm{~s} ; 55^{\circ} \mathrm{C}, 30 \mathrm{~s} ; 72{ }^{\circ} \mathrm{C}, 30 \mathrm{~s}\right] \times 35 ; 72{ }^{\circ} \mathrm{C}, 240 \mathrm{~s}$. PuReTaq Ready-To-Go PCR Beads, GE Healthcare, were used.

\subsection{Statistical Analysis}

A two-tailed $t$-test and Fishers exact test (by means of EpiInfoTM, version 7.2.2.6, from CDC, Atlanta, GA, USA) were used for calculation of $p$ and OR.

Supplementary Materials: The following are available online at http:/ /www.mdpi.com/2072-6651/11/4/190/s1, Table S1: Prevalence and factors associated with nasal S. aureus carriage, Table S2: Distribution of spa-types and clonal complexes among S. aureus from butchers and meat sellers, and from cooks, Table S3: Results from PCR for attribution to animal adapted subpopulations.

Author Contributions: Conceptualization, C.C., G.W. and W.W.; Formal analysis, F.L.; Investigation, C.C. and S.H.; Writing—original draft, C.C. and W.W.; Writing—review \& editing, F.L., G.W. and W.W.

Funding: The study was supported by the German Ministry for Research and Education, grant no. 01KI1301G (project cluster MedVetStaph). The funder had no role in study design, data collection and analysis, decision to publish, or preparation of the manuscript.

Acknowledgments: We acknowledge the valuable technical assistance of Christa Cuny and Sylvia Swetik. Furthermore, we are grateful to Gerard Krause, Helmholtz Centre for Infection Research, 38124 Braunschweig, Germany, for discussion of the results.

Conflicts of Interest: The authors declare no conflict of interest.

\section{References}

1. Cuny, C.; Friedrich, A.; Kozytska, S.; Layer, F.; Nübel, U.; Ohlsen, K.; Strommenger, B.; Walther, B.; Wieler, L.; Witte, W. Emergence of methicillin-resistant Staphylococcus aureus (MRSA) in different animal species. Int. J. Med. Microbiol. 2010, 300, 109-117. [CrossRef]

2. Fitzgerald, J.R. Livestock-associated Staphylococcus aureus: Origin, evolution and public health threat. Trends Microbiol. 2012, 20, 192-198. [CrossRef]

3. Sung, J.M.; Lloyd, D.H.; Lindsay, J.A. Staphylococcus aureus host specificity: Comparative genomics of human versus animal isolates by multistrain microarray. Microbiology 2008, 154, 1949-1959. [CrossRef]

4. Lowder, B.V.; Guinane, C.M.; Ben Zakour, N.L.; Weinert, L.A.; Conway-Morris, A.; Cartwright, R.A.; Simpson, A.J.; Rambaut, A.; Nübel, U.; Fitzgerald, J.R. Recent human-to-poultry host jump, adaptation, and pandemic spread of Staphylococcus aureus. Proc. Natl. Acad. Sci. USA 2009, 106, 19545-19550. [CrossRef]

5. Resch, G.; François, P.; Morisset, D.; Stojanov, M.; Bonetti, E.J.; Schrenzel, J.; Sakwinska, O.; Moreillon, P. Human-to-bovine jump of Staphylococcus aureus CC 8 is associated with the loss of a $\beta$-hemolysin converting prophage and the acquisition of a new staphylococcal cassette chromosome. PLoS ONE 2013, 8, e58187. [CrossRef]

6. Stegger, M.; Liu, C.M.; Larsen, J.; Soldanova, K.; Aziz, M.; Contente-Cuomo, T.; Petersen, A.; Vandendriessche, S.; Jiménez, J.N.; Mammina, C.; et al. Rapid differentiation between livestock-associated and livestock-independent Staphylococcus aureus CC398 clades. PLoS ONE 2013, 14. [CrossRef]

7. Cuny, C.; Wieler, L.H.; Witte, W. Livestock-Associated MRSA: The impact on humans. Antibiotics 2015, 4, 521-543. [CrossRef]

8. Pantosti, A. Methicillin-Resistant Staphylococcus aureus associated with animals and Its relevance to human health. Front. Microbiol. 2012. [CrossRef] 
9. Smith, T.C.; Thapaliya, D.; Bhatta, S.; Mackey, S.; Engohang-Ndong, J.; Carrel, M. Geographic distribution of livestock-associated Staphylococcus aureus in the United States. Microbes Infect. 2018, 20, 323-327. [CrossRef]

10. Chuang, Y.Y.; Huang, Y.C. Livestock-associated meticillin-resistant Staphylococcus aureus in Asia: An emerging issue? Int. J. Antimicrob. Agents. 2015, 45, 334-340. [CrossRef]

11. Kluytmans, J.A. Methicillin-resistant Staphylococcus aureus in food products: Cause for concern or case for complacency? Clin. Microbiol. Infect. 2010, 16, 11-15. [CrossRef]

12. Beneke, B.; Klees, S.; Stührenberg, B.A.; Kraushaar, B.; Tenhagen, B.A. Prevalence of methicillin-resistant Staphylococcus aureus in a fresh meat pork production chain. J. Food Prot. 2011, 74, 126-129. [CrossRef] [PubMed]

13. Vossenkuhl, B.; Brandt, J.; Fetsch, A.; Käsbohrer, A.; Kraushaar, B.; Alt, K.; Tenhagen, B.A. Comparison of spa types, SCCmec types and antimicrobial resistance profiles of MRSA Isolated from turkeys at farm, Ssaughter and from retail meat indicates transmission along the production chain. PLoS ONE 2014, 9, e96308. [CrossRef] [PubMed]

14. Cuny, C.; Layer, F.; Witte, W. Staphylococcus aureus and MRSA in thawing liquid of broiler chicken carcasses and their relation to clonal lineages from humans. Intern. J. Med. Microbiol. 2011, 301, 117.

15. Argudín, M.A.; Tenhagen, B.A.; Fetsch, A.; Sachsenröder, J.; Käsbohrer, A.; Schroeter, A.; Hammerl, J.A.; Hertwig, S.; Helmuth, R.; Bräunig, J.; et al. Virulence and resistance determinants of German Staphylococcus aureus ST398 isolates from nonhuman sources. Appl. Environ. Microbiol. 2011, 77, 3052-3060.

16. Klous, G.; Huss, A.; Heederik, D.J.; Coutinho, R.A. Human-livestock contacts and their relationship to transmission of zoonotic pathogens, a systematic review of literature. One Health 2016, 2, 65-76. [CrossRef] [PubMed]

17. Köck, R.; Loth, B.; Köksal, M.; Schulte-Wülwer, J.; Harlizius, J.; Friedrich, A.W. Persistence of nasal colonization with livestock-associated methicillin-resistant Staphylococcus aureus in pig farmers after holidays from pig exposure. Appl. Environ. Microbiol. 2012, 78, 4046-4047. [CrossRef]

18. Walter, J.; Espelage, W.; Adlhoch, C.; Cuny, C.; Schink, S.; Jansen, A.; Witte, W.; Eckmanns, T.; Hermes, J. Persistence of nasal colonisation with methicillin resistant Staphylococcus aureus CC398 among participants of veterinary conferences and occurrence among their household members: A prospective cohort study, Germany 2008-2014. Vet. Microbiol. 2017, 200, 13-18. [CrossRef] [PubMed]

19. Cuny, C.; Nathaus, R.; Layer, F.; Strommenger, B.; Altmann, D.; Witte, W. Nasal colonization of humans with methicillin-resistant Staphylococcus aureus (MRSA) CC398 with and without exposure to pigs. PLoS ONE 2009, 4, e6800. [CrossRef]

20. Becker, K.; Ballhausen, B.; Kahl, B.C.; Köck, R. The clinical impact of livestock-associated methicillin-resistant Staphylococcus aureus of the clonal complex 398 for humans. Vet. Microbiol. 2017, 200, 33-38. [CrossRef] [PubMed]

21. Deiters, C.; Günnewig, V.; Friedrich, A.W.; Mellmann, A.; Köck, R. Are cases of Methicillin-resistant Staphylococcus aureus clonal complex (CC) 398 among humans still livestock-associated? Int. J. Med. Microbiol. 2015, 305, 110-113. [CrossRef]

22. Ho, J.; O'Donoghue, M.M.; Boost, M.V. Occupational exposure to raw meat: A newly-recognized risk factor for Staphylococcus aureus nasal colonization amongst food handlers. Int. J. Hyg. Environ. Health 2014, 217, 47-53. [CrossRef]

23. Boost, M.; Ho, J.; Guardabassi, L.; O'Donoghue, M. Colonization of butchers with livestock-associated methicillin-resistant Staphylococcus aureus. Zoonoses Public Health 2013, 60, 572-576. [CrossRef]

24. De Jonge, R.; Verdier, J.E.; Havelaar, A.H. Prevalence of methicillin-resistant Staphylococcus aureus amongst professional meat handlers in the Netherlands, March-July 2008. Euro Surveill. 2010, 15, 19712. [CrossRef]

25. Krupa, P.; Bystroń, J.; Bania, J.; Podkowik, M.; Empel, J.; Mroczkowska, A. Genotypes and oxacillin resistance of Staphylococcus aureus from chicken and chicken meat in Poland. Poult. Sci. 2014, 93, 3179-3186. [CrossRef]

26. Becker, K.; Schaumburg, F.; Fegeler, C.; Friedrich, A.W.; Köck, R. Staphylococcus aureus from the German general population is highly diverse. Int. J. Med. Microbiol. 2017, 307, 21-27. [CrossRef]

27. Mehraj, J.; Akmatov, M.K.; Strömpl, J.; Gatzemeier, A.; Layer, F.; Werner, G.; Pieper, D.H.; Medina, E.; Witte, W.; Pessler, F.; et al. Methicillin-sensitive and methicillin-resistant Staphylococcus aureus nasal carriage in a random sample of non-hospitalized adult population in northern Germany. PLoS ONE 2014. [CrossRef] 
28. Holtfreter, S.; Grumann, D.; Balau, V.; Barwich, A.; Kolata, J.; Goehler, A.; Weiss, S.; Holtfreter, B.; Bauerfeind, S.S.; Döring, P.; et al. Molecular Epidemiology of Staphylococcus aureus in the General Population in Northeast Germany: Results of the Study of Health in Pomerania (SHIP-TREND-0). J. Clin. Microbiol. 2016, 54, 2774-2785. [CrossRef] [PubMed]

29. Sollid, J.U.; Furberg, A.S.; Hanssen, A.M.; Johannessen, M. Staphylococcus aureus: Determinants of human carriage. Infect. Genet. Evol. 2014, 21, 531-541. [CrossRef]

30. Sakr, A.; Brégeon, F.; Mège, J.L.; Rolain, J.M.; Blin, O. Staphylococcus aureus Nasal Colonization: An Update on Mechanisms, Epidemiology, Risk Factors, and Subsequent Infections. Front. Microbiol. 2018. [CrossRef] [PubMed]

31. Wertheim, H.F.; Melles, D.C.; Vos, M.C.; van Leeuwen, W.; van Belkum, A.; Verbrugh, H.A.; Nouwen, J.L. The role of nasal carriage in Staphylococcus aureus infections. Lancet Infect. Dis. 2005, 5, 751-762. [CrossRef]

32. Ho, J.; Boost, M.V.; O'Donoghue, M.M. Tracking sources of Staphylococcus aureus hand contamination in food handlers by spa typing. Am. J. Infect. Control. 2015, 43, 759-761. [CrossRef]

33. Miller, R.R.; Walker, A.S.; Godwin, H.; Fung, R.; Votintseva, A.; Bowden, R. Dynamics of acquisition and loss of carriage of Staphylococcus aureus strains in the community: The effect of clonal complex. J. Infect. 2014, 68, 426-439. [CrossRef]

34. Köck, R.; Werner, P.; Friedrich, A.W.; Fegeler, C.; Becker, K. Prevalence of Multiresistant Microorganisms (PMM) Study Group. New Microbes New Infect. 2015, 9, 24-34. [CrossRef]

35. Holden, M.T.; Hsu, L.Y.; Kurt, K.; Weinert, L.A.; Mather, A.E.; Harris, S.R.; Strommenger, B.; Layer, F.; Witte, W.; de Lencastre, H.; et al. A genomic portrait of the emergence, evolution, and global spread of a methicillin-resistant Staphylococcus aureus pandemic. Genome Res. 2013, 23, 653-664. [CrossRef] [PubMed]

36. Layer, F.; Stromenger, B.; Cuny, C.; Werner, G. Eigenschaften, Häufigkeit und Verbreitung von MRSA in Deutschland-Update 2013/2014. Epidemiol. Bull. 2015. Available online: https://www.rki.de/DE/ Content/Infekt/EpidBull/Archiv/2015/31/Art_01.html (accessed on 21 March 2019).

37. Tavares, A.; Miragaia, M.; Rolo, J.; Coelho, C.; de Lencastre, H. High prevalence of hospital-associated methicillin-resistant Staphylococcus aureus in the community in Portugal: Evidence for the blurring of community-hospital boundaries. Eur. J. Clin. Microbiol. Infect. Dis. 2013, 32, 1269-1283. [CrossRef]

38. Weese, J.; Avery, B.; Reid Smith, R. Detection and quantification of methicillin resistant Staphylococcus aureus (MRSA) clones in retail meat products. Lett. Appl. Microbiol. 2010, 51, 338-342. [CrossRef] [PubMed]

39. Thapaliya, D.; Forshey, B.M.; Kadariya, J.; Quick, M.K.; Farina, S.; O’ Brien, A.; Nair, R.; Nworie, A.; Hanson, B.; Kates, A.; et al. Prevalence and molecular characterization of Staphylococcus aureus in commercially available meat over a one-year period in Iowa, USA. Food Microbiol. 2017, 65, 122-129. [CrossRef] [PubMed]

40. Van Rijen, M.M.; Kluytmans-van den Bergh, M.F.; Verkade, E.J.; Ten Ham, P.B.; Feingold, B.J.; Kluytmans, J.A.; CAM Study Group. Lifestyle-Associated Risk Factors for Community-Acquired Methicillin-Resistant Staphylococcus aureus Carriage in the Netherlands: An Exploratory Hospital-Based Case-Control Study. PLoS ONE 2013. [CrossRef] [PubMed]

41. ARS-Antibiotika-Resistenz-Surveillance. Available online: https:/ /ars.rki.de (accessed on 21 March 2019).

42. Armand-Lefevre, L.; Ruimy, R.; Andremont, A. Clonal comparison of Staphylococcus aureus isolates from healthy pig-farmers, human controls, and pigs. Emerg. Infect. Dis. 2005, 11, 711-714. [CrossRef]

43. Van der Wolf, P.J.; Rothkamp, A.; Junker, K.; de Neeling, A.J. Staphylococcus aureus (MSSA) and MRSA (CC398) isolated from post-mortem samples from pigs. Vet. Microbiol. 2012, 158, 136-141. [CrossRef] [PubMed]

44. Nemati, M.; Hermans, K.; Lipinska, U.; Denis, O.; Deplano, A.; Struelens, M.; Devriese, L.; Pasmans, F.; Haesebrouck, F. Antimicrobial resistance of old and recent Staphylococcus aureus isolates from poultry: First detection of livestock-associated methicillin-resistant strain ST398. Antimicrob. Agents Chemother. 2008, 52, 3817-3819. [CrossRef]

45. Akmatov, M.K.; Mehraj, J.; Gatzemeier, A.; Strömp, J.; Witte, W.; Krause, G.; Pessler, F. Serial home-based self-collection of anterior nasal swabs to detect Staphylococcus aureus carriage in a randomized population-based study in Germany. Int. J. Infect. Dis. 2014, 25, 4-10. [CrossRef] [PubMed]

46. Martineau, F.; Picard, F.J.; Ke, D.; Paradis, S.; Roy, P.H.; Ouellette, M.; Bergeron, M.G. Development of a PCR assay for identification of staphylococci at genus ans species levels. J. Clin. Microbiol. 2001, 39, 2541-2547. [CrossRef] 
47. Cuny, C.; Abdelbary, M.; Layer, F.; Werner, G.; Witte, W. Prevalence of the immune evasion gene cluster in Staphylococcus aureus CC398. Vet. Microbiol. 2015, 177, 219-223. [CrossRef] [PubMed]

48. Strommenger, B.; Kehrenberg, C.; Kettlitz, C.; Cuny, C.; Verspohl, J.; Witte, W.; Schwarz, S. Molecular characterization of methicillin-resistant Staphylococcus aureus strains from pet animals and their relationship to human isolates. J. Antimicrob. Chemother. 2006, 57, 461-465. [CrossRef] [PubMed]

49. Cuny, C.; Layer, F.; Strommenger, B.; Witte, W. Rare occurrence of methicillin-resistant Staphylococcus aureus CC130 with a novel mecA homologue in humans in Germany. PLoS ONE 2011, 6, e24360. [CrossRef] [PubMed]

50. Schlotter, K.; Ehricht, R.; Hotzel, H.; Monecke, S.; Pfeffer, M.; Donat, K. Leukocidin genes lukF-P83 and lukM are associated with Staphylococcus aureus clonal complexes 151, 479 and 133 isolated from bovine udder infections in Thuringia, Germany. Vet. Res. 2012. [CrossRef] [PubMed]

51. Jarraud, S.; Mougel, C.; Thioulouse, J.; Lina, G.; Meugnier, H.; Forey, F.; Nesme, X.; Etienne, J.; Vandenesch, F. Relationships between Staphylococcus aureus genetic background, virulence factors, agr groups (alleles), and human disease. Infect. Immun. 2002, 70, 631-641. [CrossRef] [PubMed]

(C) 2019 by the authors. Licensee MDPI, Basel, Switzerland. This article is an open access article distributed under the terms and conditions of the Creative Commons Attribution (CC BY) license (http://creativecommons.org/licenses/by/4.0/). 